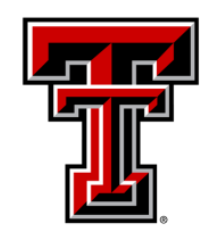

TEXAS TECH UNIVERSITY

Libraries"

\title{
The Psychology of Group Decision Making in Collection DEVELOPMENT
}

\section{The Texas Tech community has made this publication openly available. Please share how this access benefits you. Your story matters to us.}

\begin{tabular}{|l|l|}
\hline Citation & $\begin{array}{l}\text { Quinn, B. (2008). The psychology of group decision making in } \\
\text { collection development. Library Collections, Acquisitions, and } \\
\text { Technical Services, 32(1), 10-18. } \\
\text { https://doi.org/10.1016/j.lcats.2008.05.001 }\end{array}$ \\
\hline Citable Link & $\underline{\text { http://hdl.handle.net/2346/1492 }}$ \\
\hline Terms of Use & $\underline{\text { CC-BY }}$ \\
\hline
\end{tabular}


The Psychology of Group Decision Making in Collection Development 


\begin{abstract}
Significant collection development decisions are increasingly made in a group context. Despite this trend, surprisingly little research can be found in the library literature that addresses the psychological and psychosocial aspects of group interaction and their relation to the decision making process. In contrast, the field of psychology contains numerous studies of the role of group interaction in the decision making process. This article examines the psychological research on group decision making and explores how group psychology influences decision making and what the implications might be for collection development.
\end{abstract}

Keywords: group, decision, collection development, psychology 


\section{Introduction}

With the exception of monograph selection, collection development decisions are increasingly likely to be made not by individuals but by groups. Decisions regarding titles that represent a substantial investment, such as databases, or that involve an ongoing investment, such as subscriptions to journals, are commonly made in a group context. Important collection development decisions are made by groups whose members often consist of various stakeholders from different departments and at various levels in the library organization, all of whom are involved in developing the collection.

Typically, such groups take the form of a committee or team that may include subject librarians and subject team chairs, as well as heads of various departments such as acquisitions, technical services, or public services. In some instances, representatives of higher levels in the library organization may be part of the group, such as associate deans or directors. Different groups may make decisions about the various kinds of products and there may be separate groups representing different subject areas such as the humanities or sciences, or different types of resources such as serials or reference titles.

As collection development decisions become more of a group phenomenon, understanding the group and its dynamics becomes more important. How is it that group decision making differs from that of the individual? Does group interaction influence the outcome of decisions, and if so, how does this occur? How can the process of making decisions in groups be improved? These are some of the questions this article will address. 


\section{Literature Review}

Given the importance of groups and group processes to collection development, it is surprising how little attention group functioning has received in the library literature. Although there have been many articles written about decision making in the library literature, relatively few have been written about decision making in collection development and even fewer about group decision making in developing collections. Of the few studies that address the role of group processes in decision making, none appear to do so adequately.

In 1990, a book written about the process of collection development for various types of libraries examined administrative and organizational theories of decision making. The primary focus was on the work of Henry Mintzberg, in particular his seven steps or routines of decision making: recognition, diagnosis, search, design, screening, evaluation, and authorization. The author then applies those seven steps to collection development, focusing on the work of individual selectors rather than on group processes. In addition to the seven steps, the amount of discretion that a selector has can play a role in the decision process. For example, some selectors may not be allowed to evaluate or authorize the purchase of titles because these activities are performed at a higher administrative level in the library. The book concludes by recommending that selectors be given full responsibility for decision making and that selectors should become more conscious of the decision process in collecting, which will make them more confident in their choices. [1]

One early study, written fifteen years ago, traces the origins of research on group decision making back to Hawthorne studies of the 1930's done by Elton Mayo. Drawing 
largely on management literature, the author describes some key findings from the 1960's, 1970's and 1980's. Particular emphasis is placed on the optimal size of groups for decision making, and the author discusses Berelson and Steiner's theory that five members is an ideal size. Some of the statements made in the article, such as that groups may make less biased decisions than individuals or that groups with members who exhibit dominant behavior produce higher quality solutions have been called into question by recent research. [2]

One article that addresses the role of the group in making collection development decisions describes the formation of a summer study group to compile a bibliography of recommended purchases in the field of African American Studies. The team consisted of six faculty members in the social sciences and humanities and one librarian. The role of the librarian was to help faculty with their searches and to make recommendations of titles. The article does not discuss the interaction of group members other than to mention that they were excited and engaged by the project. The author mentions infrequent communication and some duplication of effort, but does not discuss the psychological aspects of group decision making. [3]

A group approach to decision making for a government documents collection was described in an article written in the mid-1990's. After the departure of its documents librarian, the library formed a working group to make decisions about the collection consisting of a reference librarian, a cataloging librarian, and one paraprofessional. The group collectively discussed decisions that had to be made, then relayed the decisions back to their respective departments. The group was continued after a new documents librarian was hired, and the head of circulation was added. The new documents librarian 
eventually became coordinator of the group. [4] The article does not discuss group interaction much, other than to state that it resulted in better orchestration of efforts and communication.

Another case study of group decision making, though unrelated to collection development, is an article about the transition to a team environment at Oregon State University. The author suggests that following a decision making model improves the quality of group decisions. Inexperienced teams learn decision making by starting with small projects and gradually working their way up to larger ones. Team members may initially be reluctant to take on the responsibility of making decisions because they are anxious about the possibility of making a poor decision. Teams may spend too much time thinking about the decision making process and not enough on the decision itself. [5]

One study done nearly ten years ago tested Hirokawa's theory of group interaction, which posits that the quality of the decision depends upon how vigilant group members are during the decision making process. The author of the study videotaped ten small groups of librarians who were each given 30 minutes to complete a group task. Each group was asked to create an instructional module designed to keep library staff informed about the latest developments in new technology. The instructional modules that the group submitted were then evaluated by three judges. Group interaction was analyzed using a form of content analysis developed by Hirokawa. Groups with the highest rated modules were found to have deemphasized procedural discussion and engaged in behavior that resulted in the generation of alternative ideas and solutions. The results supported Hirokawa's theory that group decision making effectiveness is a result of groups engaged in vigilant behaviors such as seeking factual information about the 
problem and generating and evaluating alternative solutions. [6] Although this study does focus on small group interaction with particular regard to one theory, it does not discuss collection development.

Other articles about groups in the library literature include one written about the use of project teams at Cornell to develop an online collection. The author does not really discuss the psychological aspects of the group and chooses to focus on team functions. Having a group of individuals with different talents and backgrounds is important to the effectiveness of the group. Groups facilitate the free flow of ideas and can bring a holistic comprehension of the library system that individuals working alone may lack. However, because all individuals in the group need to be consulted before making a decision, this can slow the decision process. [7]

A case study of a team appointed to manage the collection development department at the University of Nevada, Las Vegas, discusses some of the psychological aspects of group interaction. The author focuses on two aspects that she says have been neglected in the library literature-personality and how the group communicates. Concepts from pop psychology, such as the role of personality types, are drawn upon to suggest how they might influence the outcome of the group. Frequent communication among group members are key to the effective functioning of the group. The author recommends that teams should spend some time focusing on the team process and perhaps even hold a brief retreat whenever a new team leader is appointed. The team should also periodically review its priorities to see if they still seem appropriate. [8]

A more recent study addresses decision making with regard to collection development. Even though the particular emphasis of the article is on how decisions are 
made in using the conspectus to evaluate collections, there is some discussion of how group decision making is managed. The authors look at some of the literature on decision making, such as Mintzberg's research from the 1970's on strategic decision making. They discuss some theories and models of decision making, such as rational choice theory, a model of limited rationality, and Beach's theory of naturalistic decision making. The authors believe that the common denominator of all decision making theories is the need to minimize uncertainty. [9] In their study, librarians often did conspectus work in teams in an effort to reduce feelings of uncertainty regarding the findings.

While it does not discuss collection development, an article about decision making in digital library project teams does touch on some psychological aspects of the process, though the main focus is outlining a process for decision making. The article is written from a project manager's point of view, and states that the main difficulty of the project manager is to get team members to make decisions. The author breaks the decision making process down into seven key functions, which include identifying the decision to be made, grasping the context, brainstorming options and understanding their consequences, ranking the options and selecting one, reflecting on the decision taken, and finally, acting on the decision. In the decision making process, conflicting forces may be present: the courage to make a decision and fear of the consequences. In choosing among the options, self-doubt or a reluctance to be accountable may occur. The author recommends creating a risk-assessment matrix and an option assessment matrix to make the process of deciding easier. [10]

In contrast to the library literature, the field of psychology has devoted considerably more attention to how groups function in the decision making process. 
Psychologists have conducted extensive empirical studies of group dynamics and have assembled an impressive body of research on the topic which seems to have gone unnoticed by researchers in the field of librarianship. It is the purpose of this article to look at the psychological literature on how groups make decisions and explore what the implications might be for the decision making process in collection development.

\section{Patterns of Influence}

There are many different psychological and social factors that can contribute to the amount of influence an individual has over other members of the group. Perhaps the most basic is the degree of intensity with which a person prefers one particular title over another.

The situation becomes more complex when two group members or factions within a group have equally strong preferences. Group decision history tends to become a factor then, and the number of times a group member has prevailed over another member may come into consideration. If the librarian selecting for business has successfully argued in favor of adding several new databases in recent years, for example, and the selector from art has not had similar success but proposes a worthwhile title, the group may be predisposed to support purchase of the art title. Members of the group may attempt to maintain a sense of equity and fairness and let the member or faction that lost in preceding conflicts have their way. [11] The focus can shift from a consideration of the attributes of a title to the psychosocial dynamics of the group and how the librarians relate to one another. Intensity of preference and group decision history are also related to one another. A group member who was dissatisfied by a previous group selection 
decision will tend to have much stronger preferences for his or her current choices. The tendency of the group to favor a member who was disadvantaged by a previous decision may be a function of that person feeling more intensely about a current choice and the group's sense of the person having been slighted. [12]

One common way that a group can exert influence on an individual member is through direct pressure or persuasion. In many situations, however, the influence of the group on a member will take more subtle forms. One of the best known is what psychologists refer to as social comparison. When the group is discussing a title for purchase or cancellation, various members of the group are likely to make arguments in support of or against the purchase or cancellation. As this is occurring, group members are taking note of not only the quality and persuasiveness of the arguments themselves but also the number of arguments for or against the title. If the series of arguments presented tends to favor a particular decision it tends to create an unstated implicit norm that members perceive as a subtle but nonetheless powerful group norm. This emerging norm may cause various members of the group to shift their opinions to bring them into conformity with the perceived consensus of the group, thus constituting a form of social comparison as members silently compare their opinions with those of their fellow members. [13] For example, if 8 librarians in a group of 12 argue in favor of adding a title to the collection, the remaining 4 may be more inclined to play down any counterarguments or reservations that they may harbor.

The amount of time a group has to make a decision may play a role in the kind of influence that takes place in a group. Groups that have to make a decision quickly may have a greater need for consensus and resolution of differences than groups with more 
time to decide. A group that is experiencing deadline pressure may also be more likely to emphasize interpersonal agreement and harmony and focus less on information and facts. Such a group would also try to keep debate to a minimum in order to save time and reduce disagreement. This has important implications for how effectively the group functions because the greater the interaction between group members, the better the decisions they tend to make. [14] Social pressure may be an effective way to bring about a final decision but it may not be an optimal way of bringing about the best decision.

The personal qualities of group members can be a factor in influencing the decisions of the group about a particular title. Confidence tends to be an especially influential personality factor because it acts as a social cue to other group members. When a group member expresses opinions and generally behaves in a confident manner, the other members of the group interpret that member's confidence as an indication that his or her views are accurate. Confidence connotes accuracy to the other members of the group and makes them more likely to be persuaded by a confident group member, regardless of how accurate the member actually is. Thus, a group may be more likely to believe an engineering selector who speaks with great conviction about a title under consideration for purchase than a selector for English who has extensively researched a title but is less self-assured. Confident group members also tend to have more influence on the group because they tend to be more resistant to group influence and are not easily moved by group pressures. [15]

The social status of a group member can also influence other members of the group. Decision making groups for collection development may sometimes consist of mixed status membership. Some members may be subject librarians, others department 
heads, and still others may be deans or directors. High status members of the group tend to exercise normative influence, and they are able to influence other members on the basis of their organizational status. Their opinions may be given more attention and may be seen as being more important by virtue of their position, rather than the strength of their ideas or reasoning or their ability to argue a particular point. [16] They can make it more difficult for the group to weigh arguments and evidence objectively. Additionally, some members of the group may be reluctant to express opinions or cite evidence that differs from those of high status members for fear of being perceived as difficult or insubordinate. A newer, inexperienced librarian, for example, may be reluctant to voice strong criticism of a title under consideration if he or she perceives it is favored by senior colleagues.

The leader of the group can exert similar influence on group members. Leaders with an authoritarian and highly directive style may try to control the discussion. In the presence of such an individual, other members of the group may be reluctant to mention or discuss information that does not agree with the opinions expressed by the leader. If the chair of the group strongly favors the purchase of a particular title and cites various reasons, even if other members of the group are aware of information that contradicts the reasons given by the chair, they may not bring it up in an effort to avoid conflict. The result is that only certain information gets discussed and exchanged. The failure to share information may further contribute to the influence of the leader by making his opinion seem incontrovertible. [17]

Directive leadership in itself is not necessarily detrimental to group functioning. Certain kinds of directive leadership can be helpful to the group. The most important 
distinction is whether the leader is process directive or outcome directive. Process directive leaders emphasize the importance of the way decisions are made and the manner in which they are arrived at. In contrast, outcome directiveness refers to the extent to which a leader advocates a particular end result. Leaders that focus on group process tend to be rated more highly in terms of effectiveness by group members than leaders who emphasize outcomes. Groups that have a leader who emphasizes process tend to arrive at higher quality decisions and are also rated more highly in terms of effectiveness by group members than those with leaders who emphasize outcomes. [18]

This suggests that the leader of a group making decisions about the collection should place an emphasis on how the group comes to a decision rather than on the decision itself. The leader needs to emphasize the importance of gathering information about titles being considered and should give careful consideration to minority or dissenting opinions. Exposure to divergent opinions tends to result in more creative decisions. It is important for the leader to encourage discussion without advocating his or her own preferred outcome. The leader is entitled to voice an opinion but only after other members of the group have expressed their opinions. Librarians in the group that appear quiet or seem marginal to the discussion, for example, should be drawn into the group. The leader has responsibility to see that members of the group are satisfied with the manner in which the decision was arrived at. Failure to do this may compromise member support of the decision and limit the amount of member buy-in that may be needed to see the decision through.

Outcome-oriented directive leadership may contribute to a phenomenon psychologists have termed group think. This occurs when more emphasis is placed on 
group consensus than on weighing all the factors carefully and making a good decision. In such a situation, the group selectively uses information to support the leader's preference, and the decision advocated by the leader is not examined critically. A directive leader focused on a particular outcome may contribute to this situation by stating a preference early in the discussion and by systematically downplaying or disregarding attempts to discuss why that might not be the best decision. For example, a group leader experiencing pressure from a particular faculty or department to purchase a title may downplay evidence presented by librarians that the product will be little used or is overpriced. The dampening of discussion results in fewer alternatives being proposed and less thorough discussion of the advantages or disadvantages of adding or dropping a particular title. The final result is that the group often ends up adopting the decision of the leader even though group members may not agree with it. [19] The leader contributes to a situation in which individual members are reluctant to voice disagreement for fear of being stigmatized as not being team players.

It may be possible to counter the group think tendency among members by holding them individually accountable for their decisions, so that they are less able to "hide" in the collective comfort of the group situation. When members of the group anticipate that they will have to account for the quality of their decisions, they are more likely to be critical and to speak up and actively voice their opinions about how they actually feel rather than hold back. The result is that influence is more equally distributed among members rather than concentrated in the leader, and the pressure for conformity is reduced. [20] One possible way to make members more accountable individually is to 
have the members of the group evaluate each other on their performance and contributions to the group.

\section{Information Sharing}

Making high quality group decisions about the collection depends not only on the number of ideas generated but also the amount of criticism of those ideas that the group generates. This is because higher quality ideas will not emerge unless the ideas initially suggested are criticized by the group. This criticism then becomes the basis for suggesting subsequent ideas that tend to be higher quality because they incorporate the criticisms made earlier by group members. Psychologically, this creates a paradoxical situation for members of the group. On the one hand, negative evaluations lead to better quality ideas. On the other hand, being critical of ideas generated makes it riskier for group members to propose ideas, because if the idea a member proposes is criticized by another group member, the member proposing the idea may lose status within the group. It is important for the chair or leader of the group to encourage critical comments but also to try to ensure that the amount of criticism does not becomes so overwhelming that it restricts the generation of ideas. One way to achieve this is to make sure that any criticisms that are raised are not directed at individuals but to the group as a whole. [21] For example, if one librarian says something critical that appears to be directed at another librarian, the leader should immediately deflect it out to the group so that it is not personalized.

The quality of a group's decisions depends on other factors besides the generation of ideas and criticism of those ideas. It also depends on how much unique information the 
group is able to share. Unique information about a title under consideration is defined as information that only one member of the group possesses. Sharing unique information is important because it exposes members of the group to facts that they were not previously aware of. Unfortunately, psychologists know that there is a tendency for groups to primarily share information that is held in common by all members of the group. This results from the statistical likelihood that group members are more likely to mention information known to other group members and that the other group members are more likely to discuss it because they share it in common. Yet the quality of a decision depends on the ability of the group to identify and consider unique perspectives and alternatives. Less experienced members of the group may be somewhat reluctant to mention unshared information and to discuss it because by its nature it may seem risky. The risk stems from the inexperienced group members not being sure how relevant the information is, and possibly, how accurate it is. [22] The group chair and experienced members of the group can mitigate this problem by encouraging less experienced members to speak up and to avoid repeating information that has already been mentioned. The chair might look at the less experienced librarians, for example, and ask "can you think of anything that we have failed to consider?"

Another obstacle to mentioning unshared information is the tendency for group members to seek mutual approval from one another. Mentioning shared information tends to be regarded more favorably by other group members because it can be confirmed and validated. Unshared information may not be accepted as readily because it is not held in common. This leads to a situation in which group members selectively offer information 
based on how they think it will be received. This further reinforces the probabilistic tendency to mention shared information noted above. [23]

Information sharing among group members is further inhibited by poor quality decision preferences that members often bring with them to the discussion. They may favor a particular title before discussion of it has even begun because the title falls within their subject area, was requested by one of their faculty, or for a variety of reasons such as features, price, perceived usefulness, etc. Once these initial preferences have been formed, members of the group may become invested in them intellectually and emotionally, and they may be reluctant to revise their judgments, even in the face of evidence that suggests another title might be better.

This phenomenon, know as preference effect, may be further manifested during the discussion itself. Members may superficially discuss and acknowledge the merits of other titles under consideration yet still cling to their initial preference. In some instances members may reconstruct the information being discussed so that it supports their covert preference. Their receptivity to arguments may be distorted in favor of their own choice. This can result from members perceiving that information congruent with their preference is of higher quality than inconsistent information. Group members may be reluctant to change their preference in light of evidence that it is not optimal unless the evidence reaches a certain subjective threshold of superiority. [24] They may also be more critical of information that is inconsistent with their preference. The librarian leading the group should be sensitive to situations in which, for example, colleagues appear to hold strong preferences and try to encourage members to adopt a more balanced perspective. 
The sharing of information among group members is affected not only by individual preferences but also by the degree of familiarity that group members have with each other. Relatively new groups in which members do not know each other will tend to be more concerned about making a good impression and about giving socially acceptable responses. They may be concerned about how their responses are perceived and will be less likely to challenge majority opinion, propose alternatives, or offer information that runs counter to emerging consensus. Unique information is less likely to be presented among group members unfamiliar with one another, and this in turn compromises the quality of decision making.

Established group members tend to know each other and experience greater familiarity with each other. This allows them to feel comfortable enough to speak with candor, challenge one another, and propose new information. If unique information is presented to the group, members will be more likely to accept it if it comes from someone they know relatively well rather than from a relative stranger. Coming from a stranger, the same information would be more likely to be viewed as odd or eccentric. [25]

One possible way to help reduce the possibility of losing unique contributions is through assigned expertise. Assigning each member responsibility to discuss a particular title or a particular aspect of a title makes it less likely that the member's contribution will be overlooked. This frequently happens in collection development decision making groups when subject selectors propose that titles in their subject area be added or dropped. However, if the entire group is considering an expensive title or package that is interdisciplinary, it may help the quality of the decision to make different members 
responsible for researching and discussing different aspects or features of the title. For example, if the group is considering a large interdisciplinary database, members having subject expertise in these disciplines could be assigned to research the coverage of their respective areas, while another librarian might be assigned pricing and licensing terms, and another to investigate usability. With each member responsible for a particular body of information about the title, members are more likely to volunteer information and to feel that they have a unique contribution to make. [26] Their fellow members, in turn, may be more likely to regard them as being expert and to ask them more questions, helping to draw out the information and further contributing to the flow of discussion. Another way to ensure that all information about each title receives consideration is to ask members of the group to rank order the titles rather than simply select the best alternative. The process of having to rank each title makes it more likely that additional information will be presented about the title and that it will be discussed more thoroughly. In contrast, when the group only considers the best alternative, they may prematurely narrow their focus on one title or a small group of titles. Rank ordering a group of titles demands more thought about each title, more comparison between titles, and more consideration of titles that may be unpopular. It requires that information about less favored titles be reexamined and reconsidered, which may ultimately result in reevaluation. Negative information about favored titles that may have been dismissed earlier may be brought to light, resulting in a more realistic evaluation of them. [27] 


\section{Minorities, Criticism, and Controversy}

If the group strives for consensus and prefers shared information over unique information, group members may internalize these social norms and behave similarly. The likely result will be poorer quality decisions. To counter this tendency, the group chair or leader must be alert to dysfunctional norms and to call the group's attention to them. Encouraging the group to engage in deeper analysis and to be more critical and skeptical may help. For example, the chair may want to systematically and repeatedly second guess information offered about a title or assumptions that librarians in the group make about users. It may also help if the leader explains to the group that conflict and disagreement can lead to group cohesiveness, though of a different kind than consensusoriented groups. [28] It is possible to arrive at a group norm in which group members agree to disagree as long as criticism is not directed at a personal level and is done in an atmosphere of openness and mutual respect.

The chair of the group may want to go further and structure controversy into the group. This would be done solely with the intention of encouraging members of the group to analyze a decision more thoroughly. While it may generate greater doubt among members as to the optimality of their position, it may also motivate them to engage in more information seeking and exchange of perspectives. Having to articulate the rationale behind a particular position to one's fellow group members may lead members to think beyond superficial considerations and probe further to reveal new facets of a problem not previously considered. Controversy can be structured by dividing the group into two or more subgroups that would each argue a particular position. One subgroup 
could, for example, advocate the purchase or cancellation of a title while another subgroup might be assigned to argue against it. [29]

Developing a critical mindset among group members may also be achieved through the use of a devil's advocate intervention. Either the group leader or the group can select a member and assign that person the responsibility to question and challenge the positions expressed by other members of the group. The objective is to generate as many different viewpoints and to reveal all the unconsidered facets of a problem in an effort to arrive at the highest quality solution. For example, librarians who are involved in collection development often make assumptions about titles and about users that may be based on anecdotal experiences, opinions, or conjecture that should not be allowed to go unquestioned. This intervention might also spark deeper, more ruminative thinking on the part of group members and cause them to rethink their positions. [30]

If the quality of group decisions depends on how critical and discerning members of the group can be in their analysis, an important obstacle that must be faced is the expectation of group members that group relations must be harmonious. This stereotypical view is widely promoted in popular culture, and the group chair may need to emphasize to group members that disagreement and conflict can be positive and beneficial. The group leader might model such behavior, for example, by being critical but in a lighthearted rather than heavy-handed way so as not to close off discussion.The chair must also strive to manage the conflict so that the focus is not on personalizing the situation but on how the conflict will contribute to improving the group's decision. [31] He or she should also make it clear from the outset that conflict is not bad and that it is not directed at a personal level but is a means to arrive at better decisions. 
Diverging or deviant opinions may lead to conflict in the group, depending on when they are introduced into the discussion. A deviant perspective introduced early in the debate will generally be better received by other members of the group. Early in the discussion people tend to be open-minded and impressionable. As discussion wears on and it grows closer to decision time, group members are less likely to be receptive to dissenting views as pressure for consensus and closure build. The group chair should take this into account and be particularly vigilant should group members try to quickly discount or dismiss ideas introduced late in the discussion because they are tired, frustrated, or under stress. [32] For example, if one selector in the group suggests that a previously dismissed title should be reconsidered and the other members of the group balk, the chair might offer support to the selector by saying, "let's revisit this now that we have had a chance to be away from it for a while."

\section{Group Bias}

Although groups are commonly thought of as being less biased than individuals, this is not true in all cases. One type of bias that groups are vulnerable to is false consensus. This refers not only to the tendency of group members to see their own opinions as correct and appropriate, but also to their belief that other members of the group are of the same opinion. False consensus may be a result of various factors, such as the ability to retrieve more easily from memory similarities with others rather than differences. This contributes to people overestimating the amount of consensus that exists between themselves and other group members. A selector may think, for example, that other members of the group believe the title he or she is proposing to purchase is second 
only in importance to their proposals. The salience of a particular opinion can be a factor as well, because the more focused a group member is on his or her opinion the more likely he or she is to believe that others hold the same opinion. Differential construal may contribute to false consensus to the extent that a person interpreting a situation will think that others interpret it in the same way. Causal attribution may also come into play, because group members who attribute their positions to being caused by external factors will be more likely to believe that others agree with their position. A final factor that may contribute to false consensus is motivation. Group members have a need to assume that other members agree with them because doing so strengthens self-esteem and social solidarity with the group. [33] Thus, in a situation in which the group is reviewing titles to add to the collection, a group member may assume that other group members will like a particular title because he or she does. This can lead to group bias because members are making incorrect assumptions about each other as a result of fixating on their own positions.

Bias in groups can extend to the information gathering process that precedes decision making. As group members search for information, they may tend to evaluate information based on whether or not it supports their position. The more homogenous the group is in terms of preference, the stronger the confirmation bias in favor of supporting information. For example, a group of selectors, perceiving that there is an emerging group preference for a title, may choose to ignore or downplay the weaknesses of that title while focusing on its strengths. Psychologically, the consensus of the group regarding a particular alternative may make information supporting that alternative 
appear more trustworthy and convincing than non-supportive data. The group's search for information then becomes little more than a rationalization for their preference. [34]

Holding the group more accountable individually or collectively for whether they made a good decision is usually done with the intention of reducing bias. Group members, for example, may be asked to explain their decision or provide a rationale. However, this tends to have the opposite effect because it makes the group feel that they must produce compelling arguments, which then, paradoxically, makes group members more susceptible to confirmation bias. A better strategy would be to heighten the procedural accountability of the group. It might make sense, for example, for the chair or the selectors in a group to make up a procedural checklist and to check off procedures as they are followed during the meeting. This would require the group to justify not the decision itself, but how they went about making the decision. Did the group carefully collect evidence? Were the basic assumptions made by the group about a particular title critically challenged? [35]

In the process of evaluating information, negative information tends to be given more weight by group members than positive information. From a psychological standpoint, the increased salience of negative information may result from group members expecting information about new titles to be generally positive. Thus when negative information about a title appears it becomes more salient and will be more likely to be scrutinized by members of the group. [36] The group chair should be on the lookout for situations in which the group tends to dwell on and overuse negative information at the expense of positive aspects of a title. For example, if group discussion tends to 
become bogged down in negative information about a title, the chair could ask for some positive attributes in order to restore a more balanced perspective.

In addition to negative bias, groups are also vulnerable to sampling bias. This occurs when members of the group try to make decisions about the collection based on a sample that they believe is representative, but which is actually too small. The error is in underestimating the overall size of the collection relative to the size of the sample chosen. The group may ignore the flawed predictive value of the inadequate sample size and make decisions based on it. [37] This can happen in situations when the group is engaged in collection analysis or in selection situations in which the group extrapolates anticipated use of a title based on insufficiently small samples of current use.

\section{Conclusion}

Groups are commonly thought of as making better, more objective, and more rational decisions than individuals, yet the psychological research suggests that group decision making is subject to its own limitations and weaknesses. Group members may bring their own preferences and biases to the group. In the course of group interaction they may attempt to influence each other. Group history and interpersonal dynamics may affect how a decision is made. Both the personality characteristics and the social status of group members can play a factor. Individual preferences and group dynamics may influence whether and how information is shared. Thus, in many collection development decision making groups, the titles selected or not selected may be as much a function of the group as it is of the titles themselves. 
This article has attempted to point out some of the potential problems with group decision making, and has offered suggestions for how to improve the process for collection development. The chair or leader of the group should try to optimize the decision making situation. As much time as possible should be allotted to make a decision in order to avoid having the group attempt to reach premature consensus. The chair should avoid expressing a particular opinion or taking a position until other group members have had an opportunity to express their views. In some cases, group members may be reluctant to express opinions or may be overshadowed by more vocal or opinionated colleagues. The chair should be alert to this and make an effort to draw out members who may have valuable information or perspectives to share. During the course of a discussion, for example, the chair should make it a point to "check in" with quieter librarians in the group to see if they have any comments and are comfortable with what is being said. He or she may want to use the assigned expertise technique so that each team member is responsible for studying a particular part of the problem. The members themselves can help by evaluating each other on their contributions to the group. The chair must strike a delicate balance between cultivating a culture of criticism and ensuring that criticism is focused on the work and not on individuals. Groups that appear reluctant to engage in criticism can be encouraged by structuring controversy into the group. The chair should also be alert to various sources of group bias, such as focusing on negative information or attempting to make decisions based on inadequate sample size.

Perhaps the most important intervention that the group chair or leader can make is to emphasize process awareness among members of the group. The members of the group need to learn to manage their behavior as a group rather than simply focus on the task at 
hand. [38] Groups that make collection development decisions tend to focus more on the outcome, on getting a decision made, than on how best to make it. If, instead of just launching into the decision making process, the group could briefly review some important behaviors necessary to arrive at optimal decisions, the quality of the decisions that the group makes might improve. The chair, for example, could begin each meeting with a review of key group behaviors for arriving at good decisions and end the meeting with a review of how the group performed in terms of these behaviors.

Decision training could include several important points. First, the importance of thoroughly researching a title under consideration should be emphasized. This means not just gathering data and bringing it to the meeting, but making sure it is discussed. Second, it is important to stress that uncritical acceptance is to be avoided. Even if a certain member or members of the group feel strongly in favor of or against a particular title, their arguments should not be accepted at face value. The librarians in the group should be trained to call into question, for example, any rising tide of opinion that begins to surface in the group in order to prevent premature consensus. Finally, group members should be encouraged to leave no data unturned and to voice any misgivings even if they suspect they are the only person with reservations. [39]

In addition to decision training, another strategy for improving the quality of group decision making is to assign a member of the group the role of reminder. The reminder role involves being continually vigilant regarding any possible lapses in the effectiveness of the decision making process by the group. For example, if the group fails to consider a certain aspect of a title, the reminder might ask the group in a tactful, nonthreatening way if they thought they had perhaps overlooked something. Or if the group 
is too quick to leap at a decision, the reminder might suggest that some more time should be taken for analysis of particular aspects of the title or its place in the collection. Essentially, the group member assigned to the reminder role would receive training in effective group decision making processes and a list of questions to ask that might offset faulty decision processes. [40] The reminder should also be instructed to adopt a positive, constructive tone and manner when asking questions and to avoid being aggressive.

The reminder intervention is one more study in the field of psychology that echoes a common theme that runs through many of the previous studies mentioned earlier. In making group decisions about the collection, the key to effectiveness may lie not in the decision itself. Rather, it is how the group arrives at the decision that seems to be the most critical determinant of its quality. 


\section{$\underline{\text { References }}$}

[1] D. Kovacs, The decision-making process for library collections, Greenwood Press, New York (1990).

[2] M. Paris, Toward more effective group decision-making, The Southeastern Librarian 41 (1991) (4), pp.86-89.

[3] S. McKinzie, A multicultural studies collection enhancement group: a model for preemptive collection development in a small academic library, The Reference Librarian 45-46 (1994), pp.187-196.

[4] E. Theodore-Shusta and R. Wang, The team approach to the management of a government documents collection. In T. Leonhardt, Editor, Advances in collection development and resource management. 2 JAI Press, Connecticut (1996) pp.139-145.

[5] K.S. Butcher, Decision making in a team environment, Library Administration \& Management 111997 (4), pp.222-230.

[6] K. R. Tower, Small group interaction among professional librarians, College \& Research Libraries 58 (1997) (2), pp.157-171.

[7] W. Kara, The team approach in building electronic collections and services, The Serials Librarian 361999 (3/4), pp.321-335.

[8] S. S. Biery, Team management of collection development from a team member's perspective, Collection Management 252001 (3), pp.11-21.

[9] M.H. Munroe and J.E. Ver Steeg, The decision-making process in conspectus evaluation of collections: the quest for certainty, Library Quarterly 74 (2004) (2), pp.181-205. 
[10] H. F. Cervone, Making decisions: methods for digital library project teams, $O C L C$ Systems \& Services: International Digital Library Perspectives 21 (2005) (1), pp. 30-55. [11] K. P. Corfman and D. R. Lehmann, Models of cooperative group decision-making and relative influence, Journal of Consumer Research 14 (1987) (1), pp. 1-13. [12] K.P. Corfman and J.H. Steckel, Longitudinal patterns of group decisions: an exploratory analysis, Multivariate Behavioral Research 25 (1990) (3), pp.249-273.

[13] H.H. Blumberg, Group decision making and choice shift. In A.P. Hare, H.H. Blumberg, M.F. Davies, V.M. Kent, Editors, Small group research: a handbook. Ablex Publishing, Connecticut (1994), pp. 195-210.

[14] J.R. Kelly, J.W. Jackson, and S.L. Hutson-Comeaux, The effects of time pressure and task differences on influence modes and accuracy in decision-making groups, Personality and Social Psychology Bulletin 23 (1997) (1), pp.10-22.

[15] P. Zornoth and J.A. Snizek, The social influence of confidence in group decision making, Journal of Experimental Social Psychology 33 (1997) (4), pp. 345-366.

[16] Y.Ohtsubo and A. Masuchi, Effects of status difference and group size in group decision making, Group Processes \& Intergroup Relations 7 (2004) (2), pp. 161-172. [17] M.G. Cruz, D.D. Henningsen, and B.A. Smith, The impact of directive leadership on group information sampling, decisions, and perceptions of the leader, Communication Research 26 (1999) (3), pp. 349-369.

[18] R.S. Peterson, A directive leadership style in group decision making can be both virtue and vice: evidence from elite and experimental groups, Journal of Personality and Social Psychology 72 (1997) (5), pp.1107-1121. 
[19] C.R. Leana, A partial test of Janis' groupthink model: effects of group cohesiveness and leader behavior on defective decision making, Journal of Management 11 (1985) (1), pp.5-17.

[20] M.B.R. Kroon, P. Hart, and D. van Kreveld, Managing group decision making processes: individual versus collective accountability and groupthink, The International Journal of Conflict Management 2 (1991) (2), pp.91-115.

[21] S.D. Silver, A dual-motive heuristic for member information initiation in group decision making: managing risk and commitment, Decision Support Systems 15 (1995) (1), pp.83-97.

[22] G.M. Wittenbaum, Information sampling in decision-making groups: the impact of members' task-relevant status, Small Group Research 29 (1998) (1), pp. 57-84.

[23] D.D. Henningsen and M.L.M. Henningsen, The effect of individual difference variables on information sharing in decision making groups, Human Communication Research 30 (2004) (4), pp.540-555.

[24] T. Greitemeyer and S. Schulz-Hardt, Preference-consistent evaluation of information in the hidden profile paradigm: beyond group-level explorations of the dominance of shared information in group decisions, Journal of Personality and Social Psychology 84 (2003) (2), pp.322-339.

[25] D.H. Gruenfeld, E.A. Mannix, K.Y. Williams, and M.A. Neale, Group composition and decision making: how member familiarity and information distribution affect process and performance, Organizational Behavior and Human Decision Processes 67 (1996) (1), pp.1-15. 
[26] D.D. Stewart and G. Stasser, Expert role assignment and information sampling during collective recall and decision making, Journal of Personality and Social Psychology 69 (1995) (4), pp. 619-628.

[27] A.B. Hollingshead, The rank-order effect in group decision making, Organizational Behavior and Human Decision Processes 68 (1996) (3), pp. 181-193.

[28] T. Postmes, R. Spears, and S. Cihangir, Quality of decision making and group norms, Journal of Personality and Social Psychology 80 (2001) (6), pp.918-930.

[29] D. Tjosvold and R.H.G. Field, Effect of concurrence, controversy, and consensus on group decision making, The Journal of Social Psychology 125 (2001) (3) pp.355-363.

[30] L.J. Kray and A.D. Galinksy, The debiasing effect of counterfactual mind-sets: increasing the search for disconfirming information in group decisions, Organizational Behavior and Human Decision Processes 91 (2003) (1) pp.69-81.

[31] V.D. Wall, G.J. Galances, and S.B. Love, Small, task-oriented group: conflict, conflict management, satisfaction, and decision quality, Small Group Behavior 18 (1987) (1) pp.31-55.

[32] A.W. Kruglanski and D.M. Wester, Group member's reactions to opinion deviates and conformists at varying degrees of proximity to decision deadline and of environmental noise, Journal of Personality and Social Psychology 61 (1991) (2) pp.212225.

[33] P.E. Jones and P.H.Roelofsma, The potential for social contextual and group biases in team decision-making: biases, conditions and psychological mechanisms, Ergonomics 43 (2000) (8), pp.1129-1152. 
[34] S. Schulz-Hardt, D. Frey, C. Luthgens, and S. Moscovici, Biased information search in group decision making, Journal of Personality and Social Psychology 78 (2000) (4), pp.655-669.

[35] D. Frey and S. Schulz-Hardt, Confirmation bias in group information seeking and its implications for decision making in administration, business and politics. In F. Butera and G. Mugny, Editors, Social influence in social reality: promoting individual and social change. Hogrefe \& Huber, Seattle (2001) (4), pp.325-353.

[36] D.S. Stewart, Stereotypes, negativity bias, and the discussion of unshared information in decision-making groups, Small Group Research 29 (1998) (6), pp.643668.

[37] S.M. Houghton, M.Simon, K.Aquino, and C.B. Goldberg, No safety in numbers: persistence of biases and their effects on team risk perception and team decision making, Group and Organization Management 25 (2000) (4), pp.325-353.

[38] S. Jarboe, Procedures for enhancing group decision making. In R.Y. Hirokawa and M.S. Poole, Editors, Communication and group decision making. Sage Publications, California (1996) pp.345-383.

[39] J.R. Larson, P.G. Foster-Fishman, and C.B. Keys, Discussion of shared and unshared information in decision-making groups, Journal of Personality and Social Psychology 67 (1994) (3), pp. 446-461.

[40] B. Schultz, S.M. Ketrow, D.M. Urban, Improving decision quality in the small group: the role of the reminder, Small Group Research 26 (1995) (4) pp.521-541. 